\title{
PERSPECTIVES
}

\section{Who's the Real Enemy?}

\author{
Sheri King
}

I am a newcomer to student affairs. After nearly thirty years on a different career path, and after putting two sons through college, I made the decision to pursue a $\mathrm{PhD}$ in higher education. My goal is to retire from my current job and spend the remainder of my work years on a college campus as an administrator and adjunct professor. Needless to say, going back to school after what seemed to be a lifetime away from the rigors of student life was a major reality check - times have surely changed over the last three decades! However the most surprising reality I had to face was the way parents are referred to by so many in the academy.

In class settings, at conferences and workshops, in office settings, and even in the literature and media, I am constantly faced with negative attitudes and perceptions of the parents of today's college students. There seems to be an "us versus them" attitude as if the institution is in a battle with the parent over the control of the student. Terms such as "helicopter parents," "overbearing," "pushy," "controlling," and "demanding" continually surface. Are parents really that bad? I firmly believe that some parents fit those descriptions, but do all parents? Are we really at war with them? Articles proclaim the need for "parent bouncers" at Orientation-what message does that really send to parents? Are they really the enemy? Aren't we doing ourselves, and ultimately our students and institutions, a disservice by perpetuating these stereotypes?

One of my functions in my former career was to conduct customer service training for employees in a major corporation. In those training sessions, we discussed the adage that a happy customer will tell three people about his/her experience, but an unhappy customer tells ten people. (I refer to this concept as an adage because in a business training course we don't usually cite statistical research studies, even though surely at some point the research was conducted!) The point of the adage is that bad news and experiences travel farther and have a more lasting impression than good news. Is this not the same thing that we are doing when we recount stories of outrageous parent encounters? So rarely do I hear the good stories.

Let me stop here for a moment and tell you that I was a very involved parent throughout my sons' years in K-12. They attended a private school in a large metropolitan area in the South. Academically they achieved well, and they were active in sports, music, and community service. Both were admitted into several excellent universities. One son graduated from an Ivy League school and now has a rewarding career; my other son is, shall we say, a work in progress in his fifth year and is "finding himself."

Sheri King (sheri7@uga.edu) is a doctoral student at the University of Georgia. 
My involvement continued while they were in college, but the level and type of involvement changed. I will come clean here and admit that it was hard to let go the first time, but fortunately the institution did a good job of making sure, during orientation and over the course of the first year, that we understood how we could support our children - from afar-and what we should expect from them on their visits home. It took some time, but I eventually got their message. Still it was a struggle, and I became proficient at searching the institution's Web site to satisfy my need to understand what was happening. I was then in a position to respond to my son's questions and to direct him to the proper sources if he asked for my help. By the time my second son enrolled at his institution, I felt better prepared for what was ahead. It actually seemed that his institution did a better job during orientation, but in hindsight, I'm sure part of my ease at handling my role was the fact that I had a better grasp on what my role was to be. Yes, I am a proud, involved parent. I worked with my sons and their schools to help them achieve their dreams; I don't see that as a negative.

We must recognize that there is a common goal held by parents, faculty, and administrators, and that is to develop students into productive, responsible members of our society. To achieve that goal we, as student affairs professionals, need to change the way we look at parents. For starters, we need to recognize our shared goal and embrace parents as our allies, not our enemies. Today's parents have been encouraged to get involved in the lives of their children during K-12 in order to give them the best opportunities to succeed. It is only natural for parents to want to continue along those same lines when their children take the next step in their educational paths.

Parents have a lot of energy and can be very creative. We must find ways to channel that energy and creativity in directions that will benefit the student and the institution without hindering administrators and faculty. Creating a unit within student affairs that is responsible for parents' associations and parent councils will send the message to parents that they are valued. It will also provide an avenue for parents to identify opportunities for involvement.

Parents are accustomed to having parameters within which to work. Elementary and high schools are very good at letting parents know where, when, and how they can help, and what is not appropriate or acceptable. We can follow their example by setting parameters and then informing parents through orientation sessions, handbooks, newsletters, listservs, and family weekends. Many parents are unaware of the legal constraints set by FERPA and HIPAA. For that matter, many parents are not even sure what "student affairs" encompasses. If we let parents know that we exist for purposes beyond just the initial orientation, perhaps they will feel more comfortable letting their son or daughter branch out on his or her own. Information is critical to this generation of parents, and we should provide them with what they need to know.

Perhaps the most important thing we can do is challenge ourselves individually. We need to monitor our choice of language when referring to parents. Are we sending the wrong message when we use negative labels? Are we only telling the stories of bad encounters with parents? I am not saying that we need to pretend that all parents are wonderful or perfect. The stories are very entertaining and can actually be educational 
from the standpoint of what not to do, or how to improve upon a situation. Sometimes we just need a good laugh. However, we need to make a concerted effort to share the stories of the positive parent encounters as well. If we stop and think about it, those good encounters probably outnumber the bad ones. If we don't rise to the challenge, we will find that we are our own worst enemy when it comes to parents, and we will miss an opportunity to join forces with some of the best allies we could ever have.

Comments on this article may be directed to the author at sheri7@uga.edu and/or to the editor at drode@niu.edu. "Perspectives" articles represent the opinions and experiences of the author(s) and do not necessarily represent the viewpoints of the JCOT editors. 